\title{
Observation of an inner magnetosphere electric field associated with a BBF-like flow and PBIs
}

\author{
T. Johansson ${ }^{1}$, J. W. Bonnell ${ }^{2}$, C. Cully ${ }^{3}$, E. Donovan ${ }^{4}$, J. Raeder ${ }^{5}$, S. Eriksson ${ }^{1}$, L. Andersson ${ }^{1}$, R. E. Ergun ${ }^{1,6}$, \\ V. Angelopoulos ${ }^{7}$, J. McFadden ${ }^{2}$, K.-H. Glassmeier ${ }^{8}$, and I. Mann ${ }^{9}$ \\ ${ }^{1}$ Laboratory for Atmospheric and Space Physics, University of Colorado at Boulder, CO, USA \\ ${ }^{2}$ Space Sciences Laboratory, University of California, Berkeley, CA, USA \\ ${ }^{3}$ Swedish Institute of Space Physics, Uppsala, Sweden \\ ${ }^{4}$ Department of Physics and Astronomy, University of Calgary, Calgary, Canada \\ ${ }^{5}$ Space Science Center and Physics Department, University of New Hampshire, Durham, NH, USA \\ ${ }^{6}$ Department of Astrophysical and Planetary Sciences, University of Colorado at Boulder, CO, USA \\ ${ }^{7}$ IGPP/ESS, University of California, Los Angeles, CA , USA \\ ${ }^{8}$ Institute for Geophysics and Meteorology, Technical University of Braunschweig, Braunschweig, Germany \\ ${ }^{9}$ Department of Physics, University of Alberta, Edmonton, Canada
}

Received: 23 September 2008 - Revised: 25 February 2009 - Accepted: 2 March 2009 - Published: 2 April 2009

\begin{abstract}
Themis E observed a perpendicular (to the magnetic field) electric field associated with an Earthward plasma flow at $X_{\mathrm{GSM}}=-9.6 R_{E}$ on 11 January 2008. The electric field observation resembles Cluster observations closer to Earth in the auroral region. The fast plasma flow shared some characteristics with bursty bulk flows (BBFs) but did not meet the usual criteria in maximum velocity and duration to qualify as one. Themis $\mathrm{C}$ observed the same flow further downtail but Themis D, separated by only $1 R_{E}$ in azimuthal direction from Themis E, did not. At the time of the electric field and ion flow event, the all-sky imager and ground-based magnetometer at Rankin Inlet observed Poleward Boundary Intensifications (PBIs) and a negative bay signature. None of the other Themis ground-based observatories recorded any significant auroral or magnetic field activity, indicating that this was a localized activity. The joint Themis in situ and ground-based observations suggest that the two observations are related. This indicates that auroral electric fields can extend to regions much farther out than previously seen in Cluster observations.
\end{abstract}

Keywords. Magnetospheric physics (Auroral phenomena; Electric fields; Magnetosphere-ionosphere interactions)

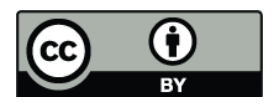

Correspondence to: T. Johansson (johtom_7@hotmail.com)

\section{Introduction}

Considerable efforts have been made to understand the Earth's auroral acceleration processes. It is known that both quasi-static and Alfvénic electric fields contribute to the auroral acceleration (e.g., Keiling et al., 2003; Karlsson et al., 2004). Alfvén waves are observed throughout the auroral oval, in the cusp and cleft. They are most common at the polar cap boundary of the auroral oval and in the premidnight sector (Chaston et al., 2003). Quasi-static electric fields in the upward (downward) current region are converging (diverging) with upward (downward) pointing, magnetic fieldaligned components (Marklund et al., 1994; Ergun et al., 1998). Direct measurements of parallel electric fields have been made both in the upward current region (Mozer and Kletzing, 1998; Ergun et al., 2002) and in the downward current region (Andersson et al., 2002). The associated potential structures can be U- or S-shaped, corresponding to monopolar or dipolar signatures in the electric field perpendicular to the magnetic field. The acceleration region of the upward current region is typically located between 5000 and $8000 \mathrm{~km}$ in altitude but sometimes reaches down to $2000 \mathrm{~km}$ (McFadden et al., 1999). In the downward current region, the acceleration region is located at lower altitudes; intense electric fields have been observed down to altitudes of $800 \mathrm{~km}$ (e.g., Marklund et al., 1997). Chaston et al. (2003) found that most of the Alfvénic acceleration occurs at altitudes above the apogee of the FAST spacecraft $(4175 \mathrm{~km})$ but that a continued acceleration of electrons takes place at lower altitudes.

Published by Copernicus Publications on behalf of the European Geosciences Union. 
On the high-altitude side, auroral electric fields (perpendicular to the magnetic field) have been observed by Cluster up to $7 R_{E}$ geocentric distance (e.g., Johansson et al., 2004). However, it is unclear if these electric fields may be observed at even larger distances along the magnetic field and how they are generated.

Fast plasma flows in the magnetotail known as bursty bulk flows (BBFs) are important for the transport of plasma in the plasma sheet. Bursty bulk flow events have been defined as 10-min duration flow enhancements and flow bursts are considered to be embedded velocity peaks of $1 \mathrm{~min}$ duration (Baumjohann et al., 1989; Angelopoulos et al., 1992). Different threshold values have been used for BBFs. Angelopoulos et al. $(1992,1994)$ used $v_{x} \geq 400 \mathrm{~km} / \mathrm{s}$, where $v_{x}$ is the velocity of the Earthward ion flow. A definition used by Schödel et al. (2001), for what they named rapid flux transport events, was $|\mathbf{v} \times \mathbf{B}| \geq 2 \mathrm{mV} / \mathrm{m}$. The characteristics of BBFs include a decreased density (leading to a reduced plasma pressure), increased magnetic field strength and decreased plasma beta (e.g., Ohtani et al., 2004; Sharma et al., 2008). Earthward BBFs have been observed at radial distances of $10 R_{E}$ (Schödel et al., 2001) but are more frequent further downtail (Angelopoulos et al., 1994). The BBFs can be relatively narrow. A recent study, taking advantage of Cluster multipoint measurements, gives the azimuthal size at the observation point as $2-3 R_{E}$ (Nakamura et al., 2004).

$\mathrm{BBFs}$ are expected to be due to reconnection and Øieroset et al. (2000) showed that high-speed, long duration flows far down the magnetotail were in fact produced by reconnection. According to the "bubble" theory (Chen and Wolf, 1999), BBFs are underpopulated flux tubes ("bubbles") and electrically polarized due to decreased density and plasma pressure inside the "bubble". The enhanced dawn-to-dusk electric field enhances the flows and launches Alfvén waves. The upward field-aligned currents predicted by this theory, connecting the BBFs to the ionosphere, are consistent with observations (Nakamura et al., 2001).

Poleward Boundary Intensifications (PBIs) occur throughout the nightside auroral oval with auroral signatures moving typically equatorward from the poleward boundary of the auroral oval. Zesta et al. (2006) showed that the orientation of the PBIs is local time dependent. PBIs are north-south aligned in the post-midnight sector but east-west aligned in the dusk sector, while they tilt from east-west to north-south direction in the premidnight sector. In a study by de la Beaujardière et al. (1994), it was shown that PBIs were related to enhanced equatorward flows in the ionosphere. A further connection with a localized increase in the nightside reconnection rate was also found. Lui et al. (1998) observed a possible relation between BBFs and optical auroral signatures moving equatorward, while Lyons et al. (1999) found that BBFs were more frequent and stronger during periods of PBIs, compared to periods without PBIs. Although a oneto-one correlation between PBIs and BBFs could not be confirmed, Zesta et al. (2006) could associate all of their ob- served PBIs with fast flow channels in the tail, occurring in the same local time sector. When no PBIs were observed in a local time sector, also no fast flows were observed in the tail in the same local time sector.

Lyons et al. (1999) claimed that PBIs are the result of the mapping to the ionosphere of the localized enhanced dawn-to-dusk electric fields that give rise to BBFs within the plasma sheet, as suggested by Henderson et al. (1998). An observation of auroral streamers moving poleward at the same time that other auroral streamers moved equatorward from a PBI led Liu et al. (2008) to propose a revised explanation. Alfvén waves generated by the BBFs were suggested to cause the auroral streamers. When the velocity of the BBF is sufficiently large, Alfvén waves launched at "outer" field lines arrive later in the ionosphere than those launched at "inner" field lines, giving the auroral streamer an apparent poleward motion. "Outer" and "inner" field lines refer to field lines further away from and closer to Earth, mapping to higher and lower latitudes, respectively. The first indication that BBFs might be responsible for significant Alfvén power generation was presented by Angelopoulos et al. (2002). They used a Geotail-Polar conjunction to show that most of the Poynting flux associated with BBFs at $18 R_{E}$ was dissipated before it reached $5 R_{E}$ and that kinetic Alfvén waves along auroral field lines were the likely dissipation mechanism.

Here, electric field and ion flow observations by Themis $\mathrm{E}$ at $10.6 R_{E}$ geocentric distance, or at $(-9.6,-2.7,-3.7) R_{E}$ in GSM coordinates, are presented. The main peak of the electric field has a magnitude of $6 \mathrm{mV} / \mathrm{m}$ and the event may be defined as a rapid flux transfer event (Schödel et al., 2001). The relation between the electric fields and the local plasma characteristics is investigated. Ground-based observations of auroral signatures at the time of the event are also discussed.

\section{Instruments}

The Themis satellites were launched on 17 February 2007 with the goal of increasing the understanding of substorms (Angelopoulos, 2008). The mission consists of five probes that during the tail science phase have apogees of 10 (Themis A), 12 (Themis D and E), 20 (Themis C) and $30 R_{E}$ (Themis B).

All satellites have identical instrumentation. In this study, measurements from the EFI electric field instrument, the FGM magnetic field instrument and the ESA particle instrument are used together with measurements from the groundbased observatories.

The EFI instrument (Bonnell et al., 2008) utilizes the double probe technique to measure the electric field in the spin plane as well as along the spin axis. In the spin plane, the two booms are 40 and $50 \mathrm{~m}$ tip-to-tip, respectively. 

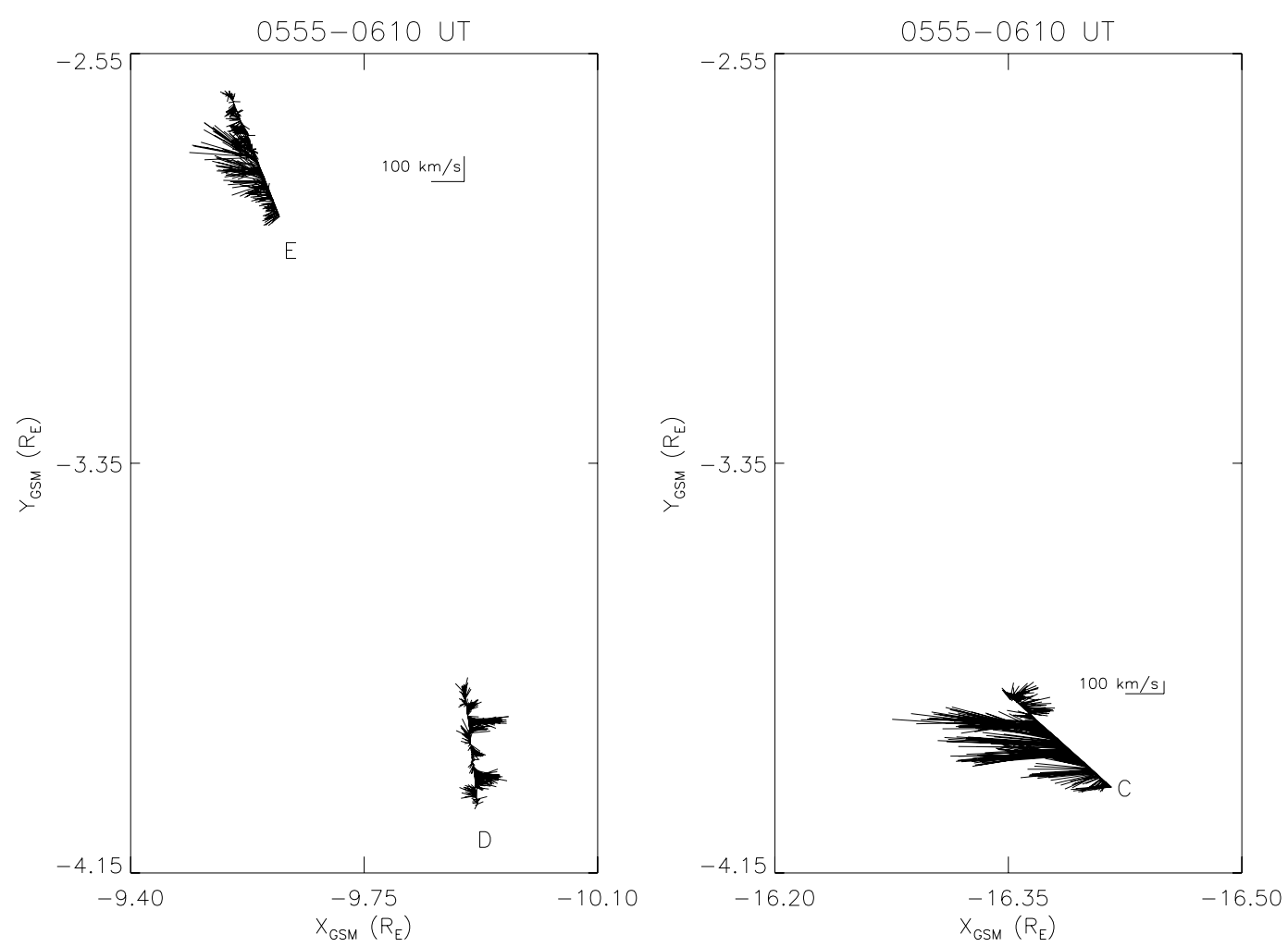

Fig. 1. The positions of Themis C (right), D and E (left) for the period 05:55-06:10 UT in the $X Y_{G S M}$-plane, with Earth to the left. Overlaid are the observed velocity vectors. The event is in the center of this interval and all three satellites move towards more negative $Y_{\mathrm{GSM}}$.

The fluxgate magnetometer, FGM, measures the background magnetic field at an accuracy of $\pm 0.01 \mathrm{nT}$ (Auster et al., 2008). The single sensor is mounted on a $2 \mathrm{~m}$ boom.

Two separate Electrostatic Analyzers (ESAs) (McFadden et al., 2008) make measurements of ions and electrons, both covering energies in the range $3 \mathrm{eV}-30 \mathrm{keV}$. The instruments have a field-of-view of $360^{\circ}$. In this study, density, velocity, and temperature moments are used.

The Themis ground segment consists of 20 all-sky imagers (ASIs) and more than 30 magnetometers, covering Canada and Alaska (Donovan et al., 2006; Mende et al., 2008) thus giving a good coverage of the nightside magnetosphere. The white light imagers have a $3 \mathrm{~s}$ resolution.

\section{Observations}

The characteristics of an electric field event observed by Themis E close to 06:00 UT on 11 January 2008 will be presented. Ground-based observations in the form of magnetometer and all-sky imager data provide a view of the auroral activity at this time. Themis $\mathrm{C}$ and $\mathrm{D}$ data are shown to give a context to the event.

The positions of Themis C, D and E at the time of this event are presented in Table 1. The orbits projected into the
GSM xy-plane are displayed in the left (Themis D and E) and right (Themis C) panels in Fig. 1, respectively, for the period 05:55-06:10 UT. All three satellites move toward more negative $Y_{\mathrm{GSM}}$. Themis E, located $9.6 R_{E}$ downtail, was separated from Themis D by approximately $1 R_{E}$, mostly in the duskward direction. Themis $\mathrm{C}$ was further down the tail at $X_{\mathrm{GSE}}=-16.4 R_{E}$. The velocity vectors overlaid on the projected orbits are discussed below. No or only sporadic data are available from Themis A and B for this time.

\subsection{Themis E}

Figure 2 displays an overview of the observations made by Themis E. The data shown in the panels are, from top to bottom, the total magnetic field, the three GSM components of the magnetic field, the magnetic field elevation angle (where $0^{\circ}$ corresponds to Earthward direction, $180^{\circ}$ to tailward direction and $90^{\circ}$ is along the GSM z-axis), the three GSM components of the ion flow velocity, the total velocity of the ion flow, ion energy-time spectrogram, ion and electron (red) densities, electron energy-time spectrogram, ion and electron (red) temperatures. The magnetic field is measured by the FGM instrument and all plasma moments have been obtained from measurements by the ESA instrument. The black, green and red lines in panels two and four are the $\mathrm{x}$, 


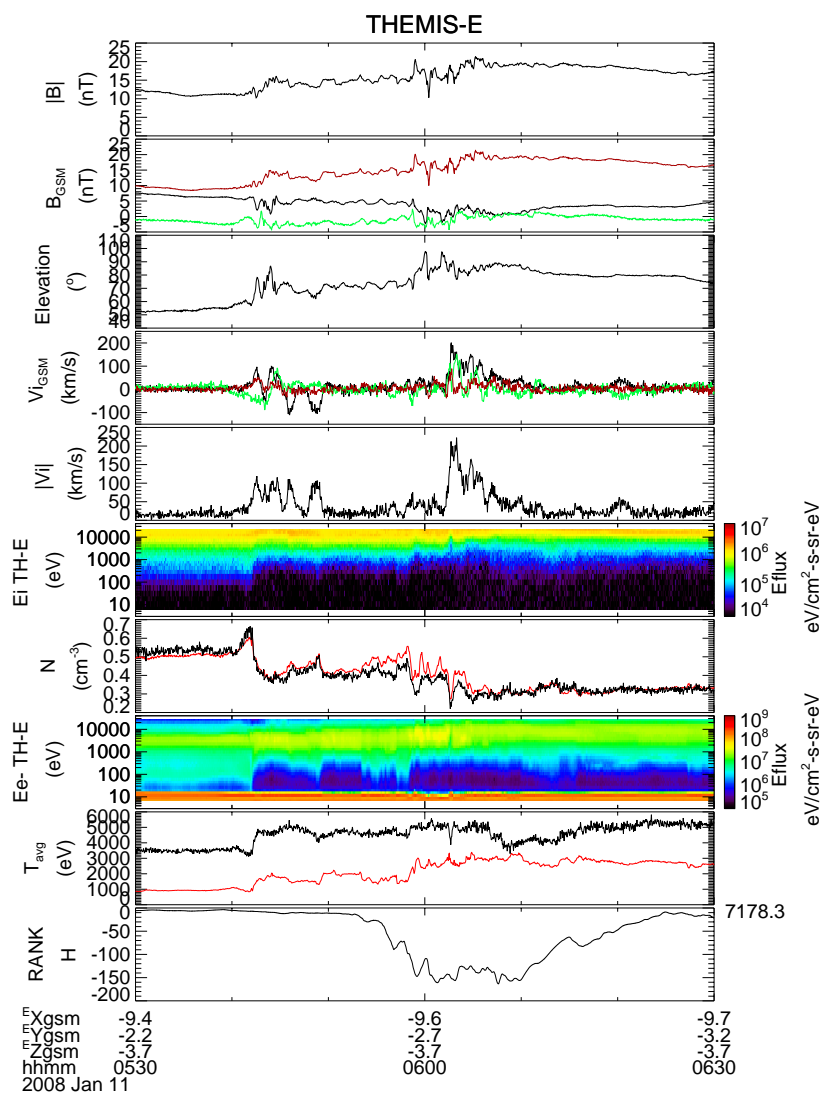

Fig. 2. Themis E observations on 11 January 2008, between 05:30 06:30 UT of, from top to bottom, the total magnetic field, the three GSM components of the magnetic field, the magnetic field elevation angle (where $0^{\circ}$ corresponds to Earthward direction, $180^{\circ}$ to tailward direction and $90^{\circ}$ is along the GSM z-axis), the three GSM components of the ion flow velocity, the total velocity of the ion flow, ion energy-time spectrogram, ion and electron (red) densities, electron energy-time spectrogram, ion and electron (red) temperatures. The black, green and red lines in panels two and four are the $\mathrm{x}, \mathrm{y}$ and $\mathrm{z}$ components of the magnetic field and the ion flow. In the last panel, the deviation in the $\mathrm{H}$ component of the magnetic field observed at Rankin Inlet, is displayed.

$\mathrm{y}$ and $\mathrm{z}$ components of the magnetic field and the ion flow. The last panel displays the deviation in the $\mathrm{H}$ component of the magnetic field observed at Rankin Inlet (see further discussion in Sect. 3.3).

The magnetic field observed by Themis $\mathrm{E}$ is dominated by the $B_{z}$ component. Disturbances in the magnetic field can be seen around 05:45 UT and 06:00 UT. At both times, the $B_{z}$ component is increasing and the $B_{x}$ component is decreasing. As a result, the elevation angle increases, indicating a more dipole-like configuration.

Close to the two dipolarization times, two ion flow periods are observed. Both tailward and Earthward flows with speeds of approximately $100 \mathrm{~km} / \mathrm{s}$ are observed between $05: 41-$
Table 1. Positions of Themis C, D and E in GSM at 06:02 UT, 11 January 2008.

\begin{tabular}{lccc}
\hline & $\mathrm{X}\left(R_{E}\right)$ & $\mathrm{Y}\left(R_{E}\right)$ & $\mathrm{Z}\left(R_{E}\right)$ \\
\hline Themis C & -16.4 & -3.88 & -6.04 \\
Themis D & -9.91 & -3.90 & -3.88 \\
Themis E & -9.58 & -2.74 & -3.72 \\
\hline
\end{tabular}

05:50 UT. During the second period (06:02:30-06:06 UT), the flow is more continous and stronger $\left(v_{x, \max } \approx 200 \mathrm{~km} / \mathrm{s}\right)$. The Earthward component is dominating but there is also a rather strong duskward component. Both flows are perpendicular to the magnetic field. The ion and electron densities decrease at the start of the two flow periods. The ion and electron temperatures increase at the first flow but while the electron temperature also increases during the second flow, the ion temperature is rather constant. This is consistent with what can be seen in the energy-time spectrogram.

The magnetometer at Rankin Inlet observes a negative bay signature (e.g., Akasofu and Meng, 1967). The decrease in the $\mathrm{H}$ component of the magnetic field occurs between 05:54-06:22 UT, with a minimum at $160 \mathrm{nT}$ below the baseline value, between 06:01-06:10 UT. Rankin Inlet is the only Themis ground-based observatory that detects any significant signature in the magnetometer data, indicating that the activity was quite localized.

Figure 3 displays $10 \mathrm{~min}$ of electric field data, focusing on the peak occuring at 06:02:30 UT. The black lines are the EFI electric field components in the GSM system (obtained from spin plane measurements and assuming $\mathbf{E} \cdot \mathbf{B}=0$ to get the third component). Overlaid in green dotted lines are $-\mathbf{v} \times \mathbf{B}$, where $\mathbf{v}$ is the ESA ion velocity moment. A good consistency is seen between the measured and inferred electric fields, giving confidence to the measurement. The total velocity of the ion flow is repeated in the fourth panel.

The magnitude of the $E_{y}$ peak at 06:02:30 UT is close to $6 \mathrm{mV} / \mathrm{m}$, corresponding to $200 \mathrm{mV} / \mathrm{m}$ at ionospheric altitude, if a dipolar configuration is assumed in a crude approximation to map the electric field. A second $E_{y}$ peak of $4.5 \mathrm{mV} / \mathrm{m}$ is seen approximately $2 \mathrm{~min}$ later. The electric field enhancements in the $E_{x}$ component are well correlated with the $E_{y}$ peaks but the $E_{x}$ enhancements are weaker. The $E_{z}$ component is close to zero throughout most of the interval, consistent with the magnetic field being predominantly in the $Z_{\mathrm{GSM}}$-direction.

Comparing the $d E / d B$ ratio with the local Alfvén velocity can reveal whether or not the event is Alfvénic in nature. Using the peak value of the electric field, $6 \mathrm{mV} / \mathrm{m}$, and the associated variation in $B_{z}, 4 \mathrm{nT}$, gives a $d E / d B$ of $150 \mathrm{~km} / \mathrm{s}$. Assuming only protons and taking the ion plasma density measured by the ESA instrument, $0.4 \mathrm{~cm}^{-3}$, and the total magnetic field, $16 \mathrm{nT}$, gives an Alfvén velocity of $556 \mathrm{~km} / \mathrm{s}$, or 3.7 times $d E / d B$. This is, considering the uncertainties in 


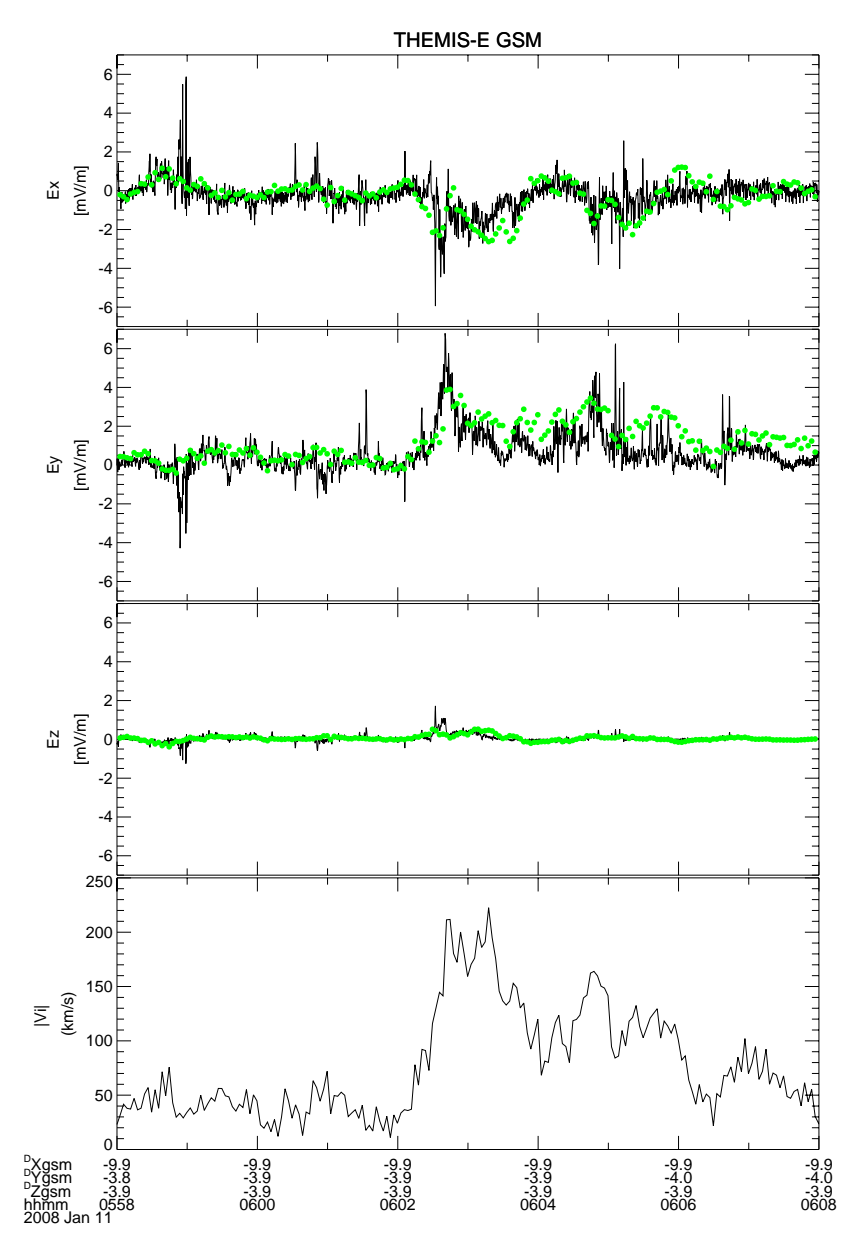

Fig. 3. The three GSM components of electric field for the same event as Fig. 1 but zoomed in at 05:58-06:08 UT. The black lines are measurements by the EFI instrument, where the third component has been calculated by assuming $\mathbf{E} \cdot \mathbf{B}=0$. The dotted green lines are $-\mathbf{v} \times \mathbf{B}$. The total velocity of the ion flow is repeated in the fourth panel.

the estimations, sufficiently close that the event can be interpreted as Alfvénic. (To examplify the uncertanties, assume instead equal amounts of $\mathrm{H}^{+}$and $\mathrm{O}^{+}$ions. This assumption gives an Alfvén velocity of $191 \mathrm{~km} / \mathrm{s}$, or 1.3 times $d E / d B$.)

Figure 3 shows that the electric field peaks (at 06:02:30 UT and 06:04:30 UT) observed by Themis $\mathrm{E}$ were found at the edges of the second Earthward flow period (06:02:3006:06 UT) in Fig. 2. This can also be seen in Fig. 4. Here, the electric field perpendicular to the magnetic field is plotted together with the parallel and perpendicular ion flows. The data have been resampled to the resolution of the magnetic field. The parallel electric field is small and omitted. To give a sense of the parallel and perpendicular directions, the magnetic field in the GSM system is also plotted. $B_{z}$ is the dominant component and therefore the parallel direction is close to the $\mathrm{z}$-axis.

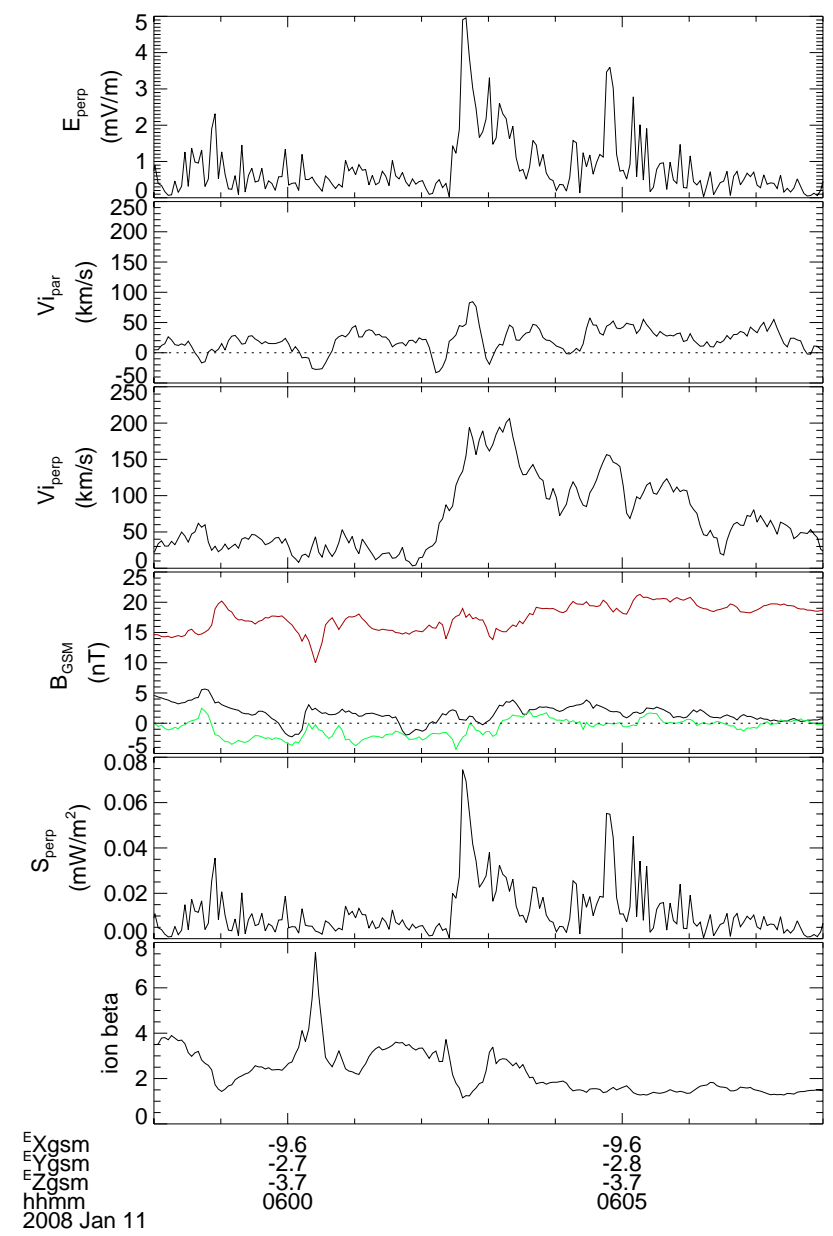

Fig. 4. Themis E observations for the same time period as in Fig. 3. The first panel displays the electric field perpendicular to the magnetic field. The ion flows parallel and perpendicular to the magnetic field is shown in the second and third panels, respectivley. The $B_{x}$ (black), $B_{y}$ (green) and $B_{z}$ (red) GSM components are shown in the fourth panel. Panel five displays the perpendicular Poynting flux, while the last panel displays the ion plasma beta.

The perpendicular, Earthward ion flow velocity rises sharply between 06:02:00 and 06:02:30 UT, stays at $\sim 200 \mathrm{~km} / \mathrm{s}$ for approximately $20 \mathrm{~s}$ and decreases during a few minutes before reaching $50 \mathrm{~km} / \mathrm{s}$. The main $E_{\perp}$ peak at 06:02:30 UT occurs when the ion flow reaches its maximum. The second electric field peak occurs close to 06:05 UT, during a gradual decrease in the ion flow.

The perpendicular component of the Poynting flux, $\mathbf{S}=\frac{1}{\mu_{0}}(\mathbf{E} \times \mathbf{B})$, has been calculated and is shown in panel five of Fig. 4. The parallel Poynting flux is more or less zero for the whole interval. However, the Earthward Poynting flux is correlated with the electric field enhancements. This indicates that the flow structure carries electromagnetic energy toward Earth. 


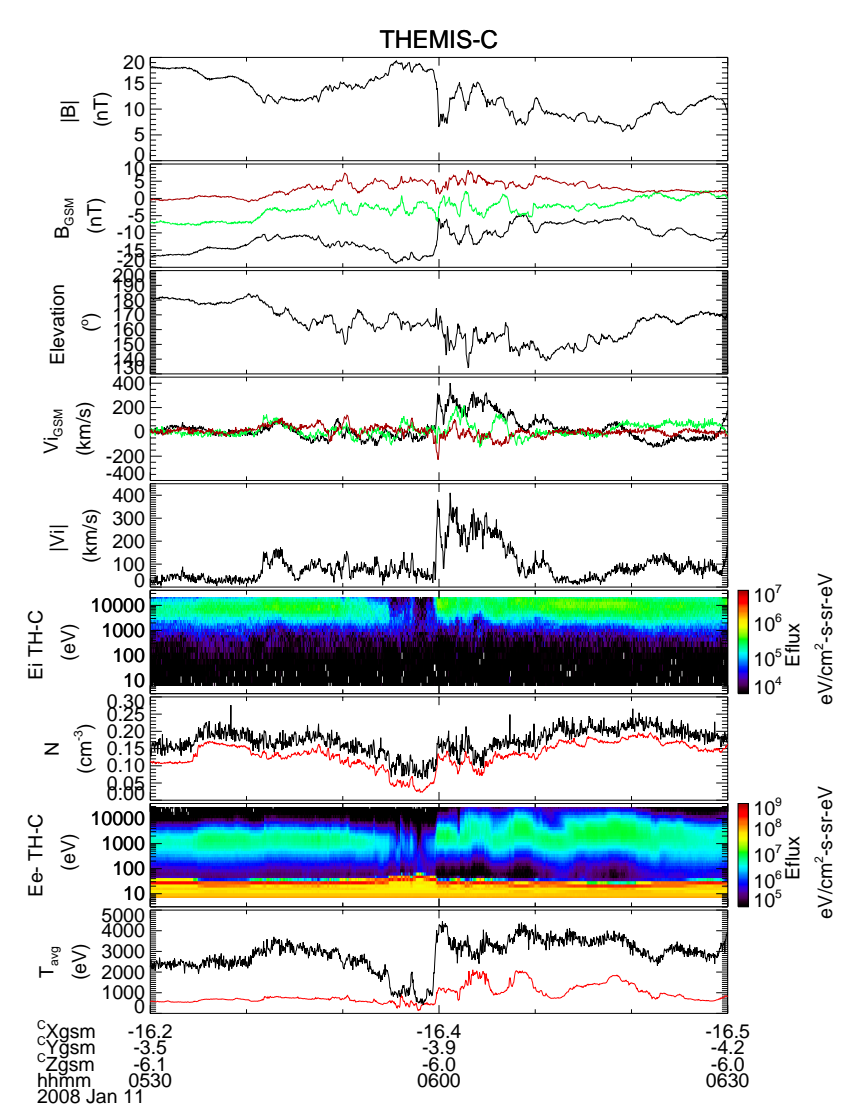

Fig. 5. Themis $\mathrm{C}$ observations in the same format and for the same time period as Fig. 2, except that the Rankin Inlet magnetometer data is not included.

The last panel in Fig. 4 shows the ion plasma beta, $\beta_{i}$. A significant drop in $\beta_{i}$ from 3 to 1 occurs at the time of the main electric field peak. Although $\beta_{i}$ recovers to almost the same value as before the drop, a continous decrease is seen across the ion flow until $\beta_{i}$ reaches 1.5 . Variations in $\beta_{i}$ suggests boundary crossings separating plasmas with different characteristics. Here, the boundary is between the Earthward flowing plasma and the background plasma of the magnetotail. $\beta_{i}$ has been used to characterize plasma boundaries associated with auroral electric fields (Johansson et al., 2006).

To summarize, Themis E observed an enhanced perpendicular electric field close to the edge of an Earthward ion flow, an Earthward Poynting flux and a sharp gradient in $\beta_{i}$. The ion and electron densities decrease during the flow regions. Although the event does not qualify as a BBF (too short duration and too low velocity), it shares some BBF characteristics and the electric field meets the criteria for a rapid flux transfer event (Schödel et al., 2001).

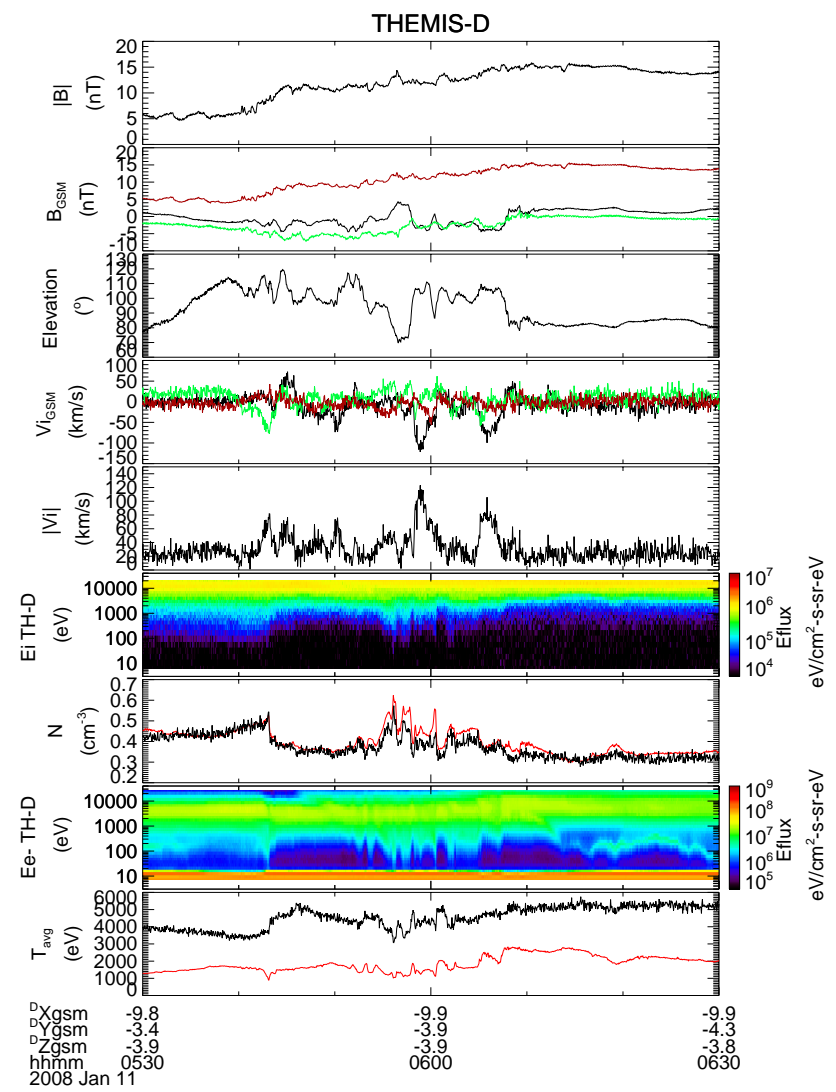

Fig. 6. Themis D observations in the same format and for the same time period as Fig. 2, except that the Rankin Inlet magnetometer data is not included.

\subsection{Themis C and D}

Figures 5 and 6 display overviews of Themis C and D data for the same time period and in the same format as in Fig. 2, except that the magnetometer data from Rankin Inlet are not repeated.

Themis $\mathrm{C}$ is located at $X_{\mathrm{GSM}}=-16.4 R_{E}$ and observes an Earthward ion flow 05:59:30-06:09 UT with a velocity of approximately $400 \mathrm{~km} / \mathrm{s}$ (panel four in Fig. 5, see also the right panel in Fig. 1). The expected time delay for the flow to reach Themis $\mathrm{E}$, at $X_{\mathrm{GSM}}=-9.6 R_{E}$, is, assuming a constant velocity, $2.4 \mathrm{~min}$. This is in quite good agreement with the observation by Themis $\mathrm{E}$ of an Earthward ion flow starting at 06:02:30 UT, considering that the ion flow slowed down to $200 \mathrm{~km} / \mathrm{s}$ by the time it reached Themis E. Note that Themis $\mathrm{C}$ and $\mathrm{E}$ are separated $2.6 R_{E}$ in the $Y Z_{\mathrm{GSM}}$ plane (see Table 1) and that this has not been taken into consideration.

The ion flow at Themis $\mathrm{C}$ is mostly directed anti-parallel to the magnetic field, which is dominated by the $B_{x}$ component. However, the magnitude of $B_{x}$ decreases at the start of the flow, making the magnetospheric configuration less 
stretched. Themis $\mathrm{C}$ observes decreases in the ion and electron densities and the ion temperature just before the Earthward flow. The region of decreased ion and electron densities is also easily identified in the energy-time spectrogram. This observation can be interpreted as Themis $\mathrm{C}$ entering the lobe region for approximately $5 \mathrm{~min}$. During the flow, the ion density gradually increases while the ion temperature rises quickly to a higher value than before the dip. The electrons have, in contrast to the ions, two temperature enhancements during the Earthward ion flow.

The particle observations made by Themis $\mathrm{D}$ are, in a large-scale sense, similar to what Themis E observes, which is to be expected given their close proximity. Some density depletion is seen in the Themis $\mathrm{D}$ ion and electron data but they are not as clearly collocated with the start of the flows as were the short depletions observed by Themis E. However, Themis $\mathrm{D}$ and $\mathrm{E}$, although only separated by approximately $1 R_{E}$ in $Y_{\mathrm{GSM}}$, make quite different ion flow observations. Two weak tailward ion flows are seen by Themis D, at 05:5806:01 UT and 06:05-06:08 UT (panel four in Fig. 6). The first ion flow occurs before the ion flow seen by Themis $\mathrm{E}$ and the second ion flow starts during the end of the Themis $\mathrm{E}$ ion flow. The difference can also be seen in the left panel in Fig. 1, which displays the 05:55-06:10 UT velocity vectors observed by Themis $\mathrm{D}$ and $\mathrm{E}$ in the $X Y_{\mathrm{GSM}}$ plane. It is clearly seen that flows at Themis E are Earthward throughout this interval, while Themis D observes flows with changing directions and two distinct but much weaker tailward flows. Hence, the ion flows at Themis D and E appear to be unrelated and this illustrates how localized fast plasma flow channels may be.

\subsection{Ground-based observations and Themis E footpoint}

The ground-based magnetometer signature at Rankin Inlet was displayed in the last panel of Fig. 2 in the form of the deviation in the $\mathrm{H}$ component. A negative bay signature was observed at the time of the Themis E electric field and ion flow observations. Figure 7 displays the $\mathrm{H}$ components of the magnetic field observed at the Themis high latitude ground stations, including Rankin Inlet (RANK). The negative bay signature observed at Rankin Inlet is the only significant signature recorded.

The optical auroral signatures observed above Rankin Inlet are Poleward Boundary Intensifications (Lyons et al., 1999). In Fig. 8, 16 panels display ASI images from Rankin Inlet between 06:02:00 and 06:03:30 UT. A keogram is shown at the top of Fig. 8 for the period 05:55-06:15 UT. In this sequence of images, brightenings appear west and east of the center of Rankin Inlet's field-of-view. A number of PBIs occur also before 06:02:00. The PBIs all appear at the poleward boundary of the diffuse aurora and they are elongated mostly in the west to east direction (but with some tilt towards northsouth direction) and expand equatorward and eastward. This

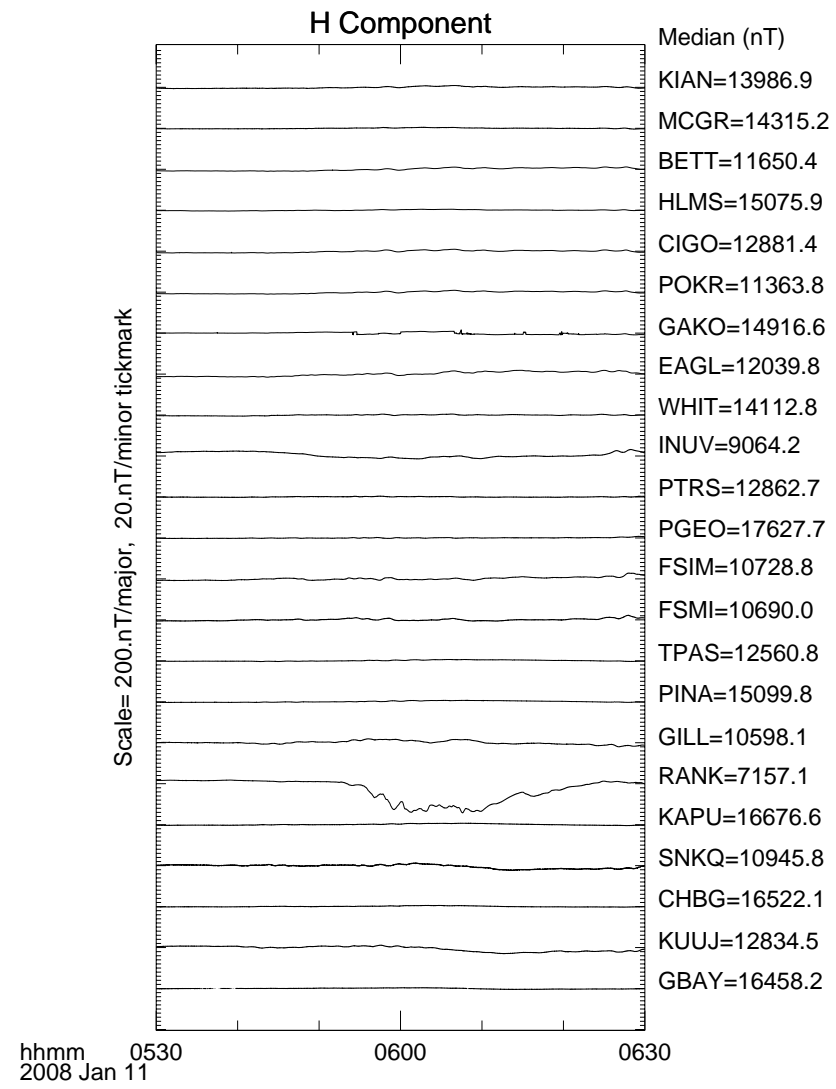

Fig. 7. H component of Themis ground magnetometer data from high latitude stations.

is consistent with the typical PBI orientation in the premidnight sector, as reported by Zesta et al. (2006).

The PBIs and the negative bay observed at Rankin Inlet were the most significant observations by the Themis ground segment. The conclusion must be that the only significant activation in the night sector at this time occurred close to Rankin Inlet. It is well known that PBIs are related to Earthward fast flows (e.g., Zesta et al., 2006). Given the Rankin Inlet observations and the lack of other auroral activity observations, it is tempting to connect the Themis E observations to the Rankin Inlet observations.

However, using the Tsyganenko T96 model (Tsyganenko, 1995) to map the Themis E location to the ionosphere resulted in a footpoint close to the Sanikiluaq (SNKQ) station, rather than Rankin Inlet (see Fig. 9). The deviation between Rankin Inlet and Themis E's Tsyganenko footpoint is $21^{\circ}$ or $1.4 \mathrm{~h}$ in MLT. Some activity is observed at Sanikiluaq, but the signature is much weaker than the Rankin Inlet signature ( -20 and $-160 \mathrm{nT}$, respectively).

In an earlier Themis event study (Angelopoulos et al., 2008), ground-based and in situ observations were better correlated when an MHD model was used to obtain the footpoint (Raeder et al., 2008). The same model, with ACE solar 

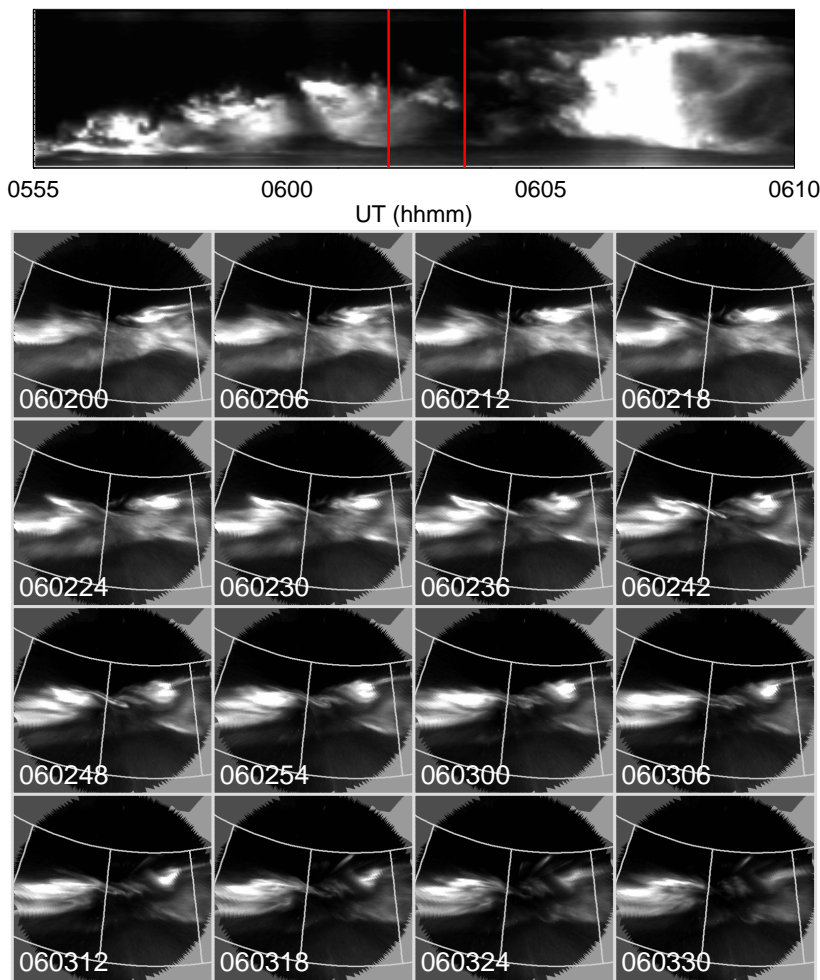

Fig. 8. Rankin Inlet all-sky images for the period 06:02:0006:03:30 UT and a keogram for the period 05:55-06:10 UT. The contours in the images are invariant latitudes $\left(70\right.$ and $\left.75^{\circ}\right)$, and invariant longitudes separated by $15^{\circ}$ or one hour of MLT. The two vertical red lines in the keogram mark the times of the first and last image.

wind data as input, has been used also for this event. The result is shown in Fig. 9, and it is seen that the footpoint of Themis E is approximately $31^{\circ}$, or $2.1 \mathrm{~h}$ in MLT, east of Rankin Inlet. The closest ground-magnetometer is at the Kuujjuarapik (KUUJ) station, where the signature is much weaker $(-40 \mathrm{nT})$ than the Rankin Inlet signature $(-160 \mathrm{nT})$. For this event, the three Interplanetary Magnetic Field and Solar Wind monitors (ACE, WIND and Geotail) made quite different observations, which mean that there is a large uncertainty in the model input.

In longitude, the Tsyganenko T96 model footpoint is closer to Rankin Inlet than the MHD model footpoint. However, in latitude, the MHD model gives a latitude that compared to the Tsyganenko model is closer to Rankin Inlet (see Fig. 9). This implies that the stretching of the magnetotail may be better captured by the MHD model.

Neither mapping technique unambigously supports a Themis E footpoint close to Rankin Inlet. Nonetheless, it can be argued that the uncertanties in the magnetic field mapping are sufficiently large for the actual footpoint to be closer to Rankin Inlet. For the MHD simulation, the input data for this event is the main source of uncertainty in the result. A more general uncertainty is related to field-aligned currents (FACs) or magnetic field line distortions, which can be caused by flows in the y-direction in the near tail. Such flows were observed by Themis E. The footpoint can be shifted in local time by one hour or more during times when FACs are present (Donovan, 1993). Here, the auroral display observed by the ASI at Rankin Inlet indicates the presence of FACs, which implies an uncertainty in the model results.

Factors that influence the footpoint shift are the intensity and location of the FAC. A more intense FAC will give a larger footpoint shift. The intensity of the FAC is unkown in this event. The model developed by Donovan (1993) indicated that the footpoint shift should be the largest at $\left|Z_{\mathrm{GSM}}\right| \sim 3.5 R_{E}$, corresponding to the boundary between Region 1 and Region 2 currents (Iijima and Poterma, 1978). The Themis $\mathrm{E}$ observation were made at $Z_{\mathrm{GSM}} \sim-3.7 R_{E}$, suggesting that the footpoint shift could be large. Precise estimates of the corrections to the two determined footpoints can not be made due to the uncertanties in the characteristics of the FACs.

Also, a one-to-one spatial correlation between PBIs and fast flows is not expected. Zesta et al. (2006) only found that PBIs and fast flows occurred in the same local time sector. For this event, where an isolated and localized activation can be identified in the ground-based data, it is likely that the Rankin Inlet and Themis E observations are related.

\section{Discussion}

Duskward electric fields, close to the edges of an Earthward ion flow, were observed by Themis E together with Earthward Poynting flux. The electric fields, the ion flow and the Poynting flux were all in a plane perpendicular to the magnetic field. The flow was associated with decreases in density and ion plasma beta. At the same time, auroral activity was observed by ground-based instruments not far (less than $2.1 \mathrm{~h}$ MLT) from the suggested footpoint.

This electric field event shares similarities with both perpendicular auroral electric field observations closer to Earth and to BBFs. However, the ion flow observed by Themis E is too slow and has a too short duration to meet the criteria for BBFs (Angelopoulos et al., 1992, 1994). Nonetheless, it is a bulk flow of plasma, predominantly Earthward, perpendicular to the magnetic field and associated with decreases in the plasma density and $\beta_{i}$, variations in the magnetic field as well as a dipolarization; characteristics in common with BBFs and flow bursts. Angelopoulos et al. (1992) also state that the $400 \mathrm{~km} / \mathrm{s}$ threshold, used in their study, "does not represent a physically significant quantity". The intensity of the electric field $(6 \mathrm{mV} / \mathrm{m})$ found at the boundary of the flow is, however, similar to the most intense peak of $E_{y}=-v_{x} \times B_{z}$ in the event studied in detail by Angelopoulos et al. (1992). In a BBF study by Schödel et al. (2001), the event selection criterion 


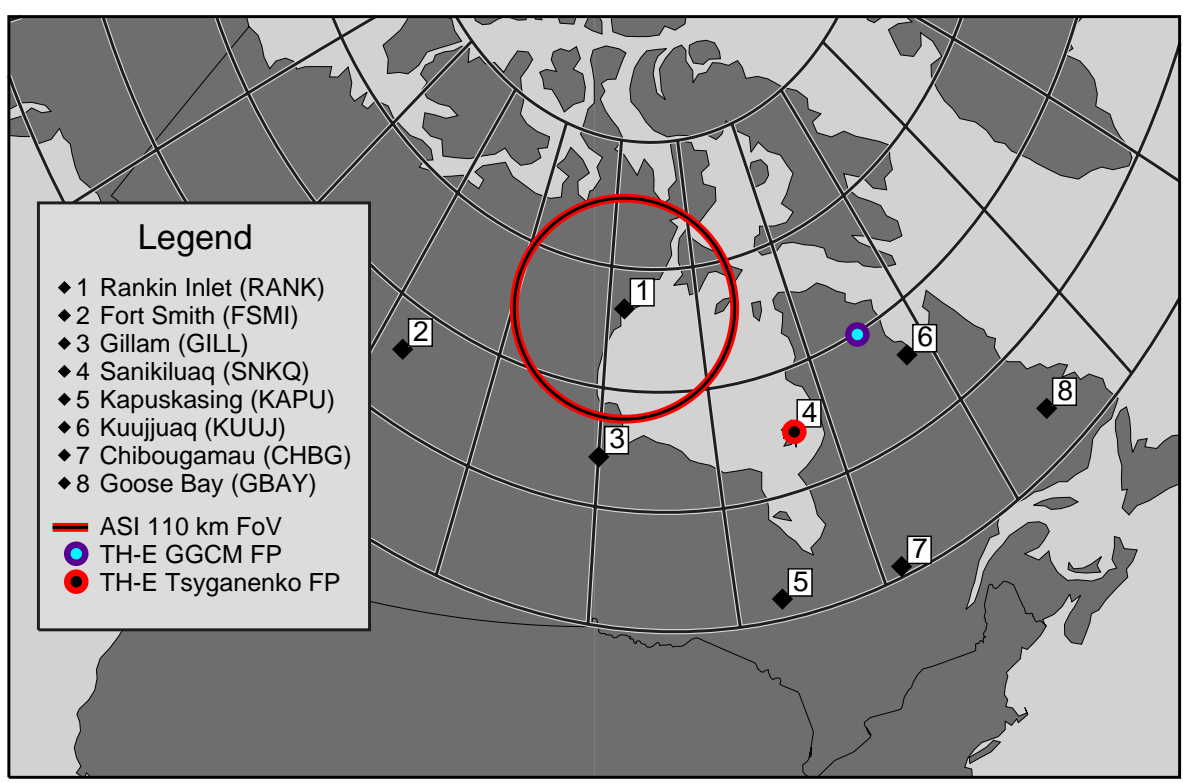

Fig. 9. Themis E footpoint obtained using the OpenGGCM MHD model (blue and purple dot) and the Tsyganenko T96 model (black and red dot), together with the locations of some ground stations. The red and black circle marks the Rankin Inlet field-of-view at $110 \mathrm{~km}$ altitude.

was not a specific value of the flow speed but a threshold in the flux transfer rate, $\left|v_{x} \times B_{z}\right|=2 \mathrm{mV} / \mathrm{m}$. The reason given for using this criterion was that the ion velocity typically decreases towards Earth and, hence, the need for a distance independent criterion. The slowing down was shown statistically by Ohtani et al. (2004), who also found that the duration of fast flows was shorter closer to Earth. A slowing down of the ion flow is observed in this event; Themis $\mathrm{C}$ observed at $X_{\mathrm{GSM}}=-16.4 R_{E}$ a speed of $400 \mathrm{~km} / \mathrm{s}$, while Themis E observed at $X_{\mathrm{GSM}}=-9.6 R_{E}$ a speed of $200 \mathrm{~km} / \mathrm{s}$. The electric field peak value of $6 \mathrm{mV} / \mathrm{m}$ in this event meets the criterion by Schödel et al. (2001).

What makes this BBF-like event interesting is the clear, intense electric field measurement perpendicular to the magnetic field. It is similar to perpendicular auroral electric field structures observed by spacecraft such as Cluster, FAST and Polar, closer to Earth. At the same time, the electric field is clearly related to the Earthward ion flow. The electric field appears to be Alfvénic $\left(d E / d B \sim v_{A}\right)$ and is associated with an Earthward Poynting flux.

It has been shown that Alfvénic electric fields are important contributors to the powering of the aurora and Alfvén waves can carry significant Poynting flux (e.g., Wygant et al., 2002; Chaston et al., 2003; Keiling et al., 2003; Mende et al., 2003; Schriver et al., 2003; Dombeck et al., 2005). The quasi-static electric field structures observed by Cluster were also associated with Earthward Poynting fluxes (e.g., Johansson et al., 2004), although one event with Poynting flux away from Earth has been reported (Liléo et al., 2008). The Cluster events were typically located at plasma boundaries (Mark- lund et al., 2004; Johansson et al., 2006). Alfvénic electric fields have also been associated with plasma boundaries (Wygant et al., 2002).

The Cluster results include observations of auroral electric fields (both Alfvénic and quasi-static (e.g., Karlsson et al., 2004)), perpendicular to the magnetic field, at geocentric distances up to $7 R_{E}$ (Johansson et al., 2005). This upper limit was set by the orbit constraints of Cluster in relation to the auroral region and whether or not that also was a physical limit could not be established. The event presented here might be an example of an auroral electric field extending far beyond that upper limit. The acceleration region, with magnetic-field-aligned electric fields, is located much closer to Earth; at altitudes of 5000-8000 km in the upward current region (McFadden et al., 1999).

If this perpendicular electric field is related to the perpendicular electric field in the auroral region, it would suggest that auroral electric fields are related to fast flows in the magnetotail. Such flows are relatively common. The observed fast flow in this event is perpendicular to the magnetic field. Fast flows can be both parallel and perpendicular to the magnetic field (Petrukoviclh et al., 2001; Raj et al., 2002). Perpendicular flows are typically found in high- $\beta$ plasma, while parallel flows are found in low- $\beta$ plasma. Since the convective flows occur in the high- $\beta$ plasma sheet (Petrukoviclh et al., 2001), the mechanism generating the auroral electric field should be found there as well. Hamrin et al. (2006) reported observations of generator regions near the boundary of the plasma sheet. The observations presented here appear to link perpendicular electric fields to the region of the 
generator mechanism and to the fast flows, which are probably generated by reconnection (Øieroset et al., 2000) tailward of $X_{\mathrm{GSE}}<-17 R_{E}$ (Angelopoulos et al., 1994).

If the negative bay observation at Rankin Inlet is interpreted as the signature of a substorm, it is a weak one and only captured by one of the Themis ground-based magnetometers. The electric field would in this case occur during the expansion phase, consistent with the results on large electric fields in the plasma sheet presented by Keiling et al. (2001).

PBIs have been related to Earthward ion flows (de la Beaujardière et al., 1994; Lyons et al., 1999). For this event, optical auroral signatures of PBIs were observed above Rankin Inlet. Lyons et al. (1999) suggested that the PBIs were caused by BBFs and Liu et al. (2008) modified that theory by saying that the BBFs launched Alfvén waves that caused the auroral brightening. The electric field observed in this event can be interpreted as Alfvénic and would then support Liu's model. Alfvén waves launched in association with flows or by some other mechanism could also be related to the set up of ionospheric electric field structures responsible for other types of aurora. The results of this study are in agreement with a general assumption that Earthward flow causes auroral displays.

\section{Summary and conclusions}

An electric field structure associated with a fast Earthward ion flow was observed by Themis E on 11 January 2008 at 06:02:30 UT. The ion flow and the electric field were both perpendicular to the magnetic field. The electric field occurred close to the edge of the Earthward flow, had a monopolar shape and a magnitude of $6 \mathrm{mV} / \mathrm{m}$ in the dawn-todusk direction. At this time, auroral activity was registered by the magnetometer and the All-Sky Imager at Rankin Inlet.

Based on the characteristics of this event and its similarities with auroral electric field events studied closer to Earth (by, e.g., Cluster) and the close collocation in time with ground-based observations of auroral signatures, it is suggested that the electric field, and the associated Earthward plasma flow, is related to the auroral PBI activity.

Statistical studies are needed to establish a connection between electric field processes in the inner magnetotail and auroral characteristics. This event study presents promising results that relate auroral activity with electric field observations at large distances along the magnetic field lines from the acceleration region.

Acknowledgements. Work by TJ was supported by a THEMIS subaward to LASP (NASA grant SA3649-26326) at the University of Colorado at Boulder.

Financial support for the work of the FGM Lead Investigator Team at the Technical University of Braunschweig by the German Ministerium für Wirtschaft und Technologie and the Deutsches Zentrum für Luft- und Raumfahrt under grant 50QP0402 is acknowledged.
Topical Editor I. A. Daglis thanks K. A. Lynch and M. Foerster for their help in evaluating this paper.

\section{References}

Akasofu, S. I. and Meng, C.-I.: Intense negative bays inside the auroral zone. I The evening sector, J. Atmos. Terr. Phys., 29, 965973, 1967.

Andersson, L., Ergun, R., Newman, D. L., McFadden, J. P., Carlsson, C. W., and Su, Y.-J.: Characteristics of parallel electric fields in the downward current region, Phys. Plasmas, 9, 3600-3609, 2002.

Angelopoulos, V.: The THEMIS mission, Space Sci. Rev., 141, 534, doi:10.1007/s11214-008-9336-1, 2008.

Angelopoulos, V., Baumjohann, W., Kennel, C. F., Coroniti, F. V., Kivelson, M. G., Pellat, R., Walker, R. J., Lühr, H., and Paschmann, G.: Bursty bulk flows in the inner central plasma sheet, J. Geophys. Res., 97, 4027-4039, 1992.

Angelopoulos, V., Kennel, C. F., Coroniti, F. V., Pellat, R., Kivelson, M. G., Walker, R. J., Russell, C. T., Baumjohann, W., Feldman, W. C., and Gosling, J. T.: Statistical characteristics of bursty bulk flow events, J. Geophys. Res., 99, 21257-21280, 1994.

Angelopoulos, V., Chapman, J. A., Mozer, F. S., Scudder, J. D., Russell, C. T., Tsuruda, K., Mukai, T., Hughes, T. J., and Yumoto, K.: Plasma sheet electromagnetic power generation and its dissipation along auroral field lines, J. Geophys. Res., 107(A8), 1181, doi:10.1029/2001JA900136, 2002.

Angelopoulos, V., Sibeck, D., Carlson, C. W., McFadden, J. P., Larson, D., Lin, R. P., Bonnell, J. W., Mozer, F. S., Ergun, R., Cully, C., Glassmeier, K. H., Auster, U., Roux, A., LeContel, O., Frey, S., Phan, T., Mende, S., Frey, H., Donovan, E., Russell, C. T., Strangeway, R., Liu, J., Mann, I., Rae, J., J.Raeder, Li, X., Liu, W., Singer, H. J., Sergeev, V. A., Apatenkov, S., Parks, G., Fillingim, M., and Sigwarth, J.: First Results from the THEMIS mission, Space Sci. Rev., 141, 453-476, doi:10.1007/s11214008-9378-4, 2008.

Auster, H. U., Glassmeier, K. H., Magnes, W., Aydogar, O., Constantinescu, D., Fischer, D., Fornacon, K. H., Georgescu, E., Harvey, P., Hillenmaier, O., Kroth, R., Ludlam, M., Narita, Y., Okrafka, K., Plaschke, F., Richter, I., Schwarzl, H., Stoll, B., Valavanoglu, A., and Wiedemann, M.: The THEMIS fluxgate magnetometer, Space Sci. Rev., 141, 235-264, doi:10.1007/s11214-008-9365-9, 2008.

Baumjohann, W., Paschmann, G., and Cattell, C. A.: Average plasma properties in the central plasma sheet, J. Geophys. Res., 94, 6597-6606, 1989.

Bonnell, J., Mozer, F. S., Delory, G. T., Hull, A. J., Ergun, R. E., Cully, C. M., Angelopoulos, V., and Harvey, P. R.: The Electric Field Instrument (EFI) for THEMIS, Space Sci. Rev., 141, 303341, doi:10.1007/s11214-008-9469-2, 2008.

Chaston, C., Bonnell, J., Carlson, C., McFadden, J., Ergun, R., and Strangeway, R.: Properties of small-scale Alfven waves and accelerated electrons from FAST, J. Geophys. Res., 108(A4), 8003, doi:10.1029/2002JA009420, 2003.

Chen, C. X. and Wolf, R. A.: Theory of thin-filament motion in Earth's magnetotail and its application to bursty bulk flows, J. Geophys. Res., 104, 14613-14626, 1999. 
de la Beaujardière, O., Lyons, L. R., Ruohniemi, J. M., FriisChristensen, E., Danielsen, C., Rich, F. J., and Newell, P. T.: Quiet-time intenstifications along the poleward auroral boundary near midnight, J. Geophys. Res., 99, 287-298, 1994.

Dombeck, J., Cattell, C., Wygant, J., Keiling, A., and Scudder, J.: Alfvén waves and Poynting flux observed simultaneously by Polar and FAST in the plasma sheet boundary layer, J. Geophys. Res., 110, A12S90, doi:10.1029/2005JA011269, 2005.

Donovan, E.: Modeling the magnetic effects of field-aligned currents, J. Geophys. Res., 98, 13529-13543, 1993.

Donovan, E., Mende, S., Jackel, B., Frey, H., Syrjsuo, M., Voronkov, I., Trondsen, T., Peticolas, L., Angelopoulos, V., Harris, S., Greffen, M., and Connors, M.: The THEMIS all-sky imaging arraysystem design and initial results from the prototype imager, J. Atmos. Sol. Terr. Phys., 68(13), 1472-1487, doi:10.1016/j.jastp.2005.03.027, 2006.

Ergun, R. E., Carlsson, C., McFadden, J., Mozer, F., Delroy, G. T., Peria, W., Chaston, C., Temerin, M., Elphic, R., Strangeway, R., Pfaff, R., Cattell, C. A., Klumpar, D., Shelley, E., Peterson, W., Moebius, E., and Kistler, L.: FAST satellite observations of electric field structures in the auroral zone, Geophys. Res. Lett., 25, 2025-2028, 1998.

Ergun, R. E., Andersson, L., Main, D., Su, Y.-J., Carlsson, C., McFadden, J., and Mozer, F.: Parallel electric fields in the upward current region of the aurora: Indirect and direct observations, Phys. Plasmas, 9, 3685-3694, 2002.

Hamrin, M., Marghitu, O., Rnnmark, K., Klecker, B., André, M., Buchert, S., Kistler, L. M., McFadden, J., Rème, H., and Vaivads, A.: Observations of concentrated generator regions in the nightside magnetosphere by Cluster/FAST conjunctions, Ann. Geophys., 24, 637-649, 2006,

http://www.ann-geophys.net/24/637/2006/.

Henderson, M. G., Reeves, G. D., and Murphree, J. S.: Are northsouth aligned auroral structures an ionospheric manifestation of bursty bulk flows?, Geophys. Res. Lett., 25, 3737-3740, 1998.

Iijima, T. and Poterma, T.: Large-Scale Characteristics of fieldaligned currents associated with substorms, J. Geophys. Res., 83, 599-615, 1978.

Johansson, T., Figueiredo, S., Karlsson, T., Marklund, G., Fazakerley, A., Buchert, S., Lindqvist, P.-A., and Nilsson, H.: Intense high-altitude auroral electric fields - temporal and spatial characteristics, Ann. Geophys., 22, 2485-2495, 2004,

http://www.ann-geophys.net/22/2485/2004/.

Johansson, T., Karlsson, T., Marklund, G., Figueiredo, S., Lindqvist, P.-A., and Buchert, S.: A statistical study of intense electric fields at 4-7 $R_{E}$ geocentric distance using Cluster, Ann. Geophys., 23, 2579-2588, 2005,

http://www.ann-geophys.net/23/2579/2005/.

Johansson, T., Marklund, G., Karlsson, T., Liléo, S., Lindqvist, P.A., Marchaudon, A., Nilsson, H., and Fazakerley, A.: On the profile of intense high-altitude auroral electric fields at magnetospheric boundaries, Ann. Geophys., 24, 1713-1723, 2006, http://www.ann-geophys.net/24/1713/2006/.

Karlsson, T., Marklund, G. T., Figueiredo, S., Johansson, T., and Buchert, S.: Separating spatial and temporal variations in auroral electric and magnetic fields by Cluster multipoint measurements, Ann. Geophys., 22, 2463-2472, 2004,

http://www.ann-geophys.net/22/2463/2004/.

Keiling, A., Wygant, J. R., Cattell, C. A., Johnson, M., Temerin, M.,
Mozer, F., Kletzing, C., Scudder, J., and Russell, C.: Properties of large electric fields in the plasma sheet at 4-7 $R_{E}$ measured with Polar, J. Geophys. Res., 106, 5779-5798, 2001.

Keiling, A., Wygant, J. R., Cattell, C. A., Mozer, F. S., and Russell, C. T.: The global morphology of wave Poynting flux: powering the aurora, Science, 299, 383-386, 2003.

Liléo, S., Marklund, G. T., Karlsson, T., Johansson, T., Lindqvist, P.-A., Marchaudon, A., Fazakerley, A., Mouikis, C., and Kistler, L. M.: Magnetosphere-ionosphere coupling during periods of extended high auroral activity: a case study, Ann. Geophys., 26, 583-591, 2008,

http://www.ann-geophys.net/26/583/2008/.

Liu, W. W., Liang, J., Donovan, E. F., Trondsen, T., Baker, G., Sofko, G., Jackel, B., Wang, C.-P., Mende, S., Frey, H. U., and Angelopoulos, V.: Observation of isolated high-speed auroral streamers and their interpretation as optical signatures of Alfvén waves generated by bursty bulk flows, Geophys. Res. Lett., 35, L04104, doi:10.1029/2007GL032722, 2008.

Lui, A. T. Y., Williams, D. J., McEntire, R. W., Ohtani, S., Zanetti, L. J., Bristow, W. A., Greenwald, R. A., Newell, P. T., Christon, S. P., Mukai, T., Tsuruda, K., Yamamoto, T., Kokubun, S., Matsumoto, H., Kojima, H., Murata, T., Fairfield, D. H., Lepping, R. P., Samson, J. C., Rostoker, G., Reeves, G. D., Rodger, A. L., and Sing, H. J.: Multipoint study of a substorm on Febuary 9, 1995, J. Geophys. Res., 103, 17333-17343, 1998.

Lyons, L. R., Nagai, T., Blanchard, G. T., Samson, J. C., Yamamoto, T., Mukai, T., Nishida, A., and Kokubun, S.: Association between Geotail plasma flows and auroral poleward boundary intensifications observed by CANOPUS photometers, J. Geophys. Res., 104, 4485-4500, 1999.

Marklund, G., Blomberg, L., Fälthammar, C.-G., and Lindqvist, P.A.: On intense diverging electric fields associated with black aurora, Geophys. Res. Lett., 21, 1859-1862, 1994.

Marklund, G., Karlsson, T., and Clemmons, J.: On low-altitude particle acceleration and intense electric fields and their relation to black aurora, J. Geophys. Res., 102, 17509-17522, 1997.

Marklund, G. T., Karlsson, T., Figueiredo, S., Johansson, T., Lindqvist, P.-A., André, M., Buchert, S., Kistler, L. M., and Fazakerley, A.: Characteristics of quasi-static potential structures observed in the auroral return current region by Cluster, Nonlin. Processes Geophys., 11, 709-720, 2004, http://www.nonlin-processes-geophys.net/11/709/2004/.

McFadden, J. P., Carlson, C. W., and Ergun, R. E.: Microstructures of the auroral acceleration region as observed by FAST, J. Geophys. Res., 104, 14453-14480, 1999.

McFadden, J. P., Carlson, C., Larson, D., Angelopoulos, V., Ludlam, M., Abiad, R., Elliott, B., Turin, P., and Marckwordt, M. The THEMIS ESA plasma instrument and in-flight calibration, Space Sci. Rev., 141, 277-302, doi:10.1007/s11214-008-94402, 2008.

Mende, S. B., Carlson, C. W., H. U. Frey, T. J. I., and Gèrard, J.-C.: IMAGE FUV and in situ FAST particle observations of substorm aurorae, J. Geophys. Res., 108(A4), 8010, doi:10.1029/2002JA009413, 2003.

Mende, S. B., Harris, S. E., Frey, H. U., Angelopoulos, V., Russell, C. T., Donovan, E., Jackel, B., Greffen, M., and Peticolas, L. M.: The THEMIS array of ground based observatories for the study of auroral substorms, Space Sci. Rev., 141, 357-387, doi:10.1007/s11 214-008-9380-x, 2008. 
Mozer, F. S. and Kletzing, C. A.: Direct observations of large, quasi-static, parallel electric fields in the auroral acceleration region, Geophys. Res. Lett., 25, 1629-1632, 1998.

Nakamura, R., Schödel, W. B. R., Brittnacher, M., Sergeev, V. A., Kubyshkina, M., Mukai, T., and Liou, K.: Earthward flow bursts, auroral streamers, and small expansions, J. Geophys. Res., 106, 10791-10802, 2001.

Nakamura, R., Baumjohann, W., Mouikis, C., Kistler, L. M., Runov, A., Volwerk, M., Asano, Y., Vörös, Z., Zhang, T. L., Rème, H., and Balogh, A.: Spatial scale of high-speed flows in the plasma sheet observed by Cluster, Geophys. Res. Lett., 31, L09804, doi:10.1029/2004GL019 558, 2004.

Ohtani, S., Shay, M. A., and Mukai, T.: Temporal structure of the fast convective flow in the plasma sheet: Comparison between observations and two-fluid simulations, J. Geophys. Res., 109, A03210, doi:10.1029/2003JA010 002, 2004.

Øieroset, M., Phan, T. D., Lin, R. P., and Sonnerup, B. U. O.: Walén and variance analyses of high-speed flows observed by Wind in the midtail plasma sheet: Evidence for reconnection, J. Geophys. Res., 105, 25247-25263, 2000.

Petrukoviclh, A. A., Baumjohann, W., Nakamura, R., Schödel, R., and Mukai, T.: Are earthward bursty bulk flows convective or field-aligned?, J. Geophys. Res., 106, 21211-21215, 2001.

Raeder, J., Larson, D., Li, W., Kepko, E. L., and Fuller-Rowell, T.: OpenGGCM simulations for the THEMIS mission, Space Sci. Rev., 141, 535-555, doi:10.1007/s11 214-008-9421-5, 2008.

Raj, A., Phan, T., Lin, R. P., and Angelopoulos, V.: Wind survey of high-speed bulk flows and field-aligned beams in the near-Earth plasma sheet, J. Geophys. Res., 107(A12), 1419, doi:10.1029/2001JA007547, 2002.
Schödel, R., Baumjohann, W., Nakamura, R., Sergeev, V. A., and Mukai, T.: Rapid flux transport in the central plasma sheet, J. Geophys. Res., 106, 301-313, 2001.

Schriver, D., Ashour-Abdalla, M., Strangeway, R., Richard, R., Klezting, C., Dotan, Y., and Wygant, J.: FAST/Polar conjunction study of field-aligned auroral acceleration and corresponding magnetotail drivers, J. Geophys. Res., 108(A9), 8020, doi:10.1029/2002JA009426, 2003.

Sharma, A. S., Nakamura, R., Runov, A., Grigorenko, E. E., Hasegawa, H., Hoshino, M., Louarn, P., Owen, C. J., Petrukovich, A., Sauvaud, J.-A., Semenov, V. S., Sergeev, V. A., Slavin, J. A., Sonnerup, B. U. Ö., Zelenyi, L. M., Fruit, G., Haaland, S., Malova, H., and Snekvik, K.: Transient and localized processes in the magnetotail: a review, Ann. Geophys., 26, 9551006, 2008, http://www.ann-geophys.net/26/955/2008/.

Tsyganenko, N. A.: Modeling the Earth's magnetospheric magnetic field confined within a realistic magnetopause, J. Geophys. Res., 100, 5599-5612, 1995.

Wygant, J. R., Keiling, A., Cattell, C., Lysak, R., Temerin, M., Mozer, F., Kletzing, C., Scudder, J., Streltsov, V., Lotko, W., and Russell, C.: Evidence for kinetic Alfvén waves and parallel electron energization at $4-6 R_{E}$ altitudes in the plasma sheet boundary layer., J. Geophys. Res., 107(A8), 1201, doi:10.1029/2001JA900113, 2002.

Zesta, E., Lyons, L., Wang, C.-P., Donovan, E., Frey, H., and Nagai, T.: Auroral poleward boundary intensifications (PBIs): Their two-dimensional structure and associated dynamics in the plasma sheet, J. Geophys. Res., 111, A05201, doi:10.1029/2004JA010640, 2006. 